\title{
Attentiveness to Early Warning Drought Information: Implications for Policy Support and Climate Risk Reduction in Ghana
}

\author{
Peter Dok Tindan $^{1} \cdot$ Divine Odame Appiah $^{1} \cdot$ Alexander Yao Segbefia $^{1}$
}

Accepted: 6 December 2021/Published online: 11 January 2022

(C) The Author(s) 2022

\begin{abstract}
Successful drought planning is dependent on the generation of timely and accurate early warning information. Yet there is little evidence to explain the extent to which crop farmers pay attention to and assimilate early warning drought information that aids in the policy formulation in support of drought risk reduction. A socioecological survey, using a structured questionnaire administered to 426 crop farming households, was carried out in the Talensi District of the Upper East Region, Ghana. The data analytic techniques used were frequency tables, relative importance index, and multinomial logistics embedded in SPSS v.20 software. The results show that crop farmers predominantly rely on agricultural extension officers for early warning drought information, with an estimated $78 \%$ of them paying little to very much attention to the information. The likelihood ratio Chi-square test showed that there is a significant improvement in fit as $X^{2}$ $(20)=96.792, p<0.000$. Household status, average monthly income, and age were the significant predictors for crop farmers paying no attention at all to early warning drought information, while household status was the only significant factor among those paying a little attention. The drive to build a climate-resilient society with effective early warning centers across Ghana will receive $60 \%$ lower support from crop farmers paying no to a little attention as compared to farmers paying very much attention to early warning drought information. Broader stakeholder engagements should be carried out to harness inclusive
\end{abstract}

Peter Dok Tindan

peterdoktindan@yahoo.com

1 Department of Geography and Rural Development, Kwame Nkrumah University of Science and Technology, Kumasi, Ashanti Region, Ghana support from crop farmers to build a climate-resilient society in Ghana.

Keywords Attentiveness to early drought warning $\cdot$ Climate risk $\cdot$ Drought risk reduction - Ghana

\section{Introduction}

Climate change around the world is manifesting in increasing frequencies of droughts, floods, heat waves, dry spells, and extreme rises in temperature, and these have aggravated the vulnerabilities of social and biophysical systems (Burchfield and Gilligan 2016; Radeva et al. 2018). Drought is seen as the worst of the climate hazards because it is insidious in nature, large scale, and generates cumulative effects (Wilhite 2006; Burchfield and Gilligan 2016; Tadesse and Dejere 2018). To prepare for, anticipate, and handle the damaging effects of climate events, the Sendai Framework for Disaster Risk Reduction 2015-2030 recommends that the actions for early warning systems (EWSs) should include access to data and information, identifying views from the frontline, considering political threats and vulnerabilities, and finding ways to talk about disaster risk creation processes at a larger scale (Marchezini 2020).

The United Nations International Strategy for Disaster Reduction (UNISDR 2009) explains EWSs as a set of capacities, not just a single ability, which is concerned with the timely and meaningful generation and dissemination of warning information to enable individuals, communities, and organizations threatened by hazards to prepare and act appropriately to minimize or reduce harm or loss. Drought early warning systems, Boken (2009) argued, are concerned with alerting the public of the possibility of 
upcoming drought and creating awareness of the drought management team. The significance of drought early warning cannot be downplayed because successful drought planning is dependent on the generation of timely and accurate early warning information (Boken 2009). Drought monitoring and early warning systems are significant to provide information for vulnerable groups in hotspots to plan, prepare, mitigate, and recover from drought (Tadesse et al. 2008; Mishra and Singh 2010; Antwi-Agyei et al. 2014; Ault et al. 2014; Ramkar and Yadav 2018).

There is relevant literature on drought and early warning systems across the globe (Boken 2009; Muguti and Maposa 2012; Antwi-Agyei et al. 2014; Baudoin et al. 2014; Cunha et al. 2019). The most reliable early warning information is often generated through state-of-the-art global climate data models (Muguti and Maposa 2012; Appiah and Boafo 2014). At the Ghana country level, the Ghana Meteorological Agency (GMet) generates and also issues early warning information on rainfall, temperature, wind speed and direction, evaporation, and sunshine hours. These data are issued as daily forecasts and seasonal forecasts to the general public as well as target populations including crop farmers. The communication outlets include radio, television, text messaging, and social media platforms, especially WhatsApp. These forecasts provide insights on the occurrence of dry spells, droughts, floods, and dust storms and strong winds. Aninagyei and Appiah (2014) identified an extreme focus on rainfall and temperature forecasting. At the local level, crop farmers use indigenous agroecological systems such as monitoring the flowering and fruiting of trees including the baobab tree (Adansonia Digitata) and the shea tree (Vitellaria paradoxa) to generate early warning drought information (Antwi-Agyei et al. 2014).

The development of effective early warning systems cannot be an end in itself. It is necessary to consider the varying capabilities and capacities of the people at risk and to question whether they can clearly understand the warning information and act appropriately (Baudoin et al. 2014). Local people, especially crop farmers, often do not have the ability to interpret the technical and scientific measurements of climate risk (Salite 2019; Ember et al. 2021). A growing issue that should attract the interest of the scientific community and policy actors at all levels is the need to understand the level of attention that crop farmers pay to early warning information on drought as a specific event, and on climate change in general.

The concept of attentiveness is one of the positive affective reactions or experiences people express when they hear information about an adverse event (Watson et al. 1988). Weiss and Cropanzano (1996) indicated that affective experiences are formed based on the emotional reactions exhibited by a person when faced with adverse events. According to Alhakami and Slovic (1994) these affective experiences are formed based on people's perception of the information about the given product, risk, or person. The reaction can be positive or negative, and the difference lies in how the information is perceived. In a situation where the perceived information indicates that the benefit is high, the risk inferred is perceived as low. When the information indicates that the risk is low, the benefit inferred is perceived as high, and these perceptions collectively define positive affective reactions. But where the information indicates that the benefit is low, a higher risk is inferred, and when the information indicates that the risk is high, the benefit inferred is low, and this is what constitutes negative affective reactions (Alhakami and Slovic 1994). Taylor (1991) also explained that the nature of any event will inform the strength of the corresponding reactions.

Explaining the level of attentiveness to early warning drought information is necessary because attentiveness generally points out people's environmental awareness and support for environmental policy (Switzer and Vedlitz 2017). Understanding the level of attentiveness to early warning information provides a clue to how crop farmers are supporting or will provide support for environmental policy in general and drought management policy in particular, especially in the light of global efforts to build climate-resilient societies. The government of Ghana has the goal to build a climate-resilient society that can rely on effective early warning and response systems, where everyone has a broad understanding of climate hazards (MESTI 2013). A key consideration in achieving this vision is to understand how vulnerable groups, especially crop farmers, pay attention to early warning information on climate risks including drought. This requires empirical studies to explore the issues around the level of attentiveness of vulnerable groups to drought risk in Ghana. But there is little explanation of attentiveness of end-users to early warning drought information at the local level in Ghana.

Discrete emotions generally explain people's cognitive judgement and sensitivity to climate events as well as support for climate change policies (Watson et al. 1988; Weiss and Cropanzano 1996; Sundblad et al. 2007). Thus, attentiveness is useful in explaining people's sensitivity to climate events like drought risk. A vast amount of research has explained the varied factors that differentiate sensitivity of vulnerable groups to climate risk and drought in particular. In relation to crop farmers, the influence of demographic and socioeconomic characteristics in explaining the differentiated sensitivity to climate risk and drought in particular is highly emphasized (Allen 2003; Brooks 2003; Bang 2008; Binita et al. 2015; Owusu et al. 2019). In the Ghanaian context, gender, class, culture, race, age, mental health, household composition and size, 
literacy status, and available resources have been identified as the significant determinants of differentiated sensitivity to climate change (Abdul-Razak and Kruse 2017; Owusu et al. 2019; Wrigley-Asante et al. 2019). But no prior study has attempted to explain how demographic and socioeconomic characteristics of crop farmers explain the differentiated levels of attentiveness to early warning drought information in Ghana. This study was therefore timely and relevant because the findings contribute to closing empirical knowledge gaps.

The study was conducted in the Talensi District of the Upper East Region. This district has $97 \%$ of households engaged in crop farming (GSS 2014), despite the fact that it is located within the estimated $35 \%$ of land area prone to drought in Ghana (UNECA 2007). Given the proneness to drought of the Talensi District and the entire Upper East Region in Ghana, the district was selected for a case study that was guided by three research questions:

(1) What are the known sources of early warning drought information for drought monitoring among crop farmers in Talensi District?

(2) What is the level of attentiveness of crop farmers to early warning drought information in Talensi District?

(3) To what extent do the demographic and socioeconomic characteristics of crop farmers predict their attentiveness to early warning drought information in Talensi District?

\section{Study Area}

The study was carried out in the Talensi District of the Upper East Region of Ghana in West Africa (Fig. 1) in the spring of 2019. The district capital is Tongo. The district has fragile climatic and ecological conditions. The rainy season in Talensi District spans the period between May and October. The annual minimum and maximum rainfall values are $880 \mathrm{~mm}$ and $1110 \mathrm{~mm}$, respectively, with a mean annual rainfall of $950 \mathrm{~mm}$. The pre-season is characterized by a higher maximum temperature of $45^{\circ} \mathrm{C}$ recorded in March and April every year. However, during the dry season, the district records a minimum temperature of $12^{\circ} \mathrm{C}$, especially in December (GSS 2014).

Despite the fragile climate, $97 \%$ of households are engaged in crop farming. These farmers cultivate food crops including rice, millet, maize, groundnut, cowpea, and sorghum mainly for subsistence. However, the soil is shallow, of low fertility and organic matter content, and predominantly coarse in texture. The district has some scattered rock outcrops and upland slopes but is overall undulating with slopes ranging from 10 to 50 degrees (GSS 2014).

\section{Research Methods}

This section outlines the methodology that was employed in the study. The specific issues discussed include research design and sampling, data collection, and data analysis.
Fig. 1 Map of Talensi District, Ghana

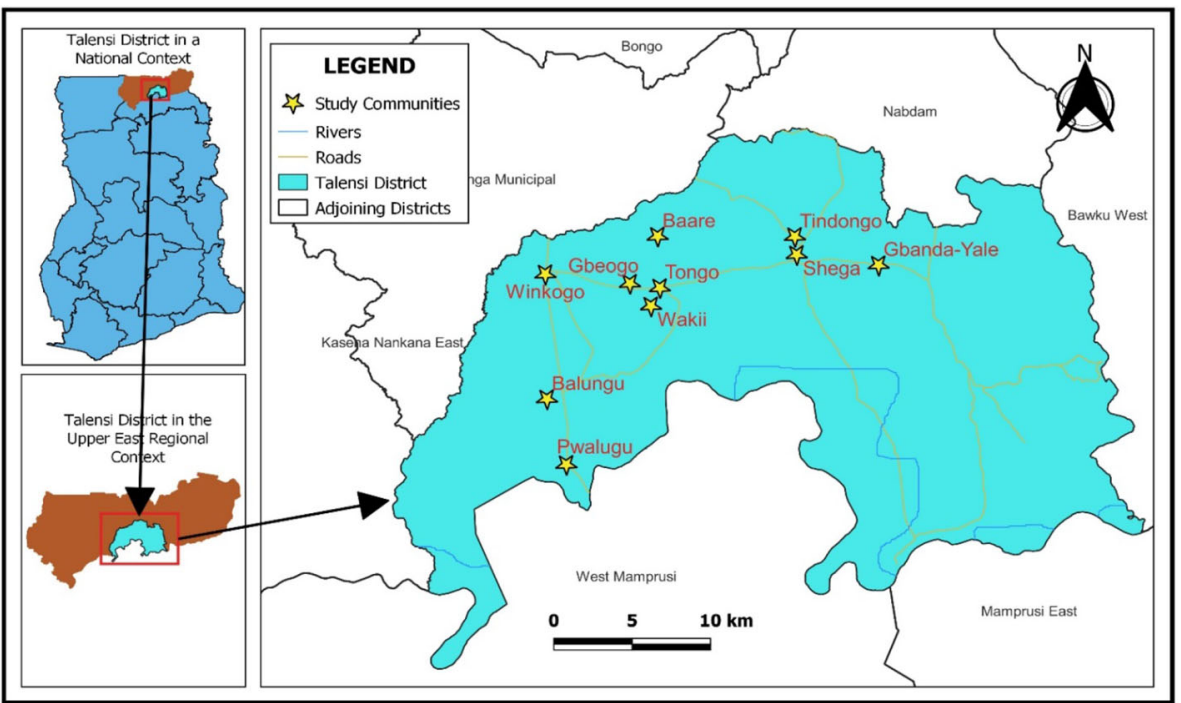




\section{Research Design and Sampling}

The data for this study came from a household survey that was conducted in Talensi District between March and June 2019. To select the study participants, a four-tier cluster sampling process was used. In the first stage, all crop farming households were divided into three strata following the three clusters of administrative area councils of the district's administrative structure. In the second stage, a list or register of the number of communities within each of the three area councils was obtained from the District Assembly. A simple random sampling technique was used to select three communities each from the three area councils: Winkogo, Balungu, and Pwalugu (in West Area Council); Baare, Tongo, and Wakii (in Central Area Council); and Tindongo, Shega, and Gbanda-Yale (in East Area Council). In the third stage, a register of the number of crop farming households in the nine selected communities was compiled. Based on the respective number of households, a proportionate sampling technique was used to select the participating crop farming households from each community (Table 1). The last stage of sampling involved the selection of the household respondents, which was done following a simple random sampling without replacement procedure.

The unit of analysis was the crop farming household, and any member who had the right to make and take decisions regarding household crop farming was qualified to be interviewed. The average size of crop farming households in the district is 5.2 persons. A representative sample was arrived at following the formula used by Saunders et al. (2007). The formula is presented as $n=N /$ $\left\{1+\mathrm{N}\left(\alpha^{2}\right)\right.$, where $\mathrm{n}$ is the sample size; $\mathrm{N}$ is the total number of crop farming households; and $\alpha$ is the margin of error or statistical significance (which is estimated at 5\%). The computation yielded a required sample of 389 households. But considering a non-response rate of $10 \%$, an approximated sample of 430 households was used. Out of the 430 households approached and who participated in the survey, an overall participation rate of $99.1 \%$ was achieved $(\mathrm{N}=426)$.

The eligibility criteria for participation required that respondents should be crop farmers who have cultivated crops in the area for at least one year. The survey instrument was administered to the household head or any other member of the household who was 18 years or older who could make decisions that affected the household's crop farming activities.

\subsection{Data Collection}

The study used a questionnaire as the main data collection instrument. In the design of the questionnaire, the concept of attentiveness to early warning drought information was explored on a three-point Likert scale $(1=$ not at all, $2=\mathrm{a}$ little, $3=$ very much). Drought is a complex climate phenomenon and is not characterized by single climate factors (Wilhite 2006). Though lack of rainfall is a predominant characteristic other factors such as soil moisture, relative humidity, temperature, and wind are significant in characterizing drought (Wilhite 2006; Radeva et al. 2018). Therefore, early warning information can be in relation to any of these factors or their complex interplay. However, the study assessed attentiveness to early warning information on the general scale, not in relation to any of the drought characterizing factors. We focused on the general scale assessment following the argument of Watson et al. (1988) that attentiveness as latent variable of affect can be assessed on the general time scale. The demographic and socioeconomic characteristics taken into account included gender, household status, age, marital status, average monthly income, formal education, religion, Information

Table 1 Proportionate sample size in the nine study communities in Talensi District, Ghana

\begin{tabular}{llcc}
\hline Area council & Name of community & Number of households & Sampled crop farming households \\
\hline West Area Council & Winkogo & 1330 & 113 \\
& Balungu & 329 & 28 \\
& Pwalugu & 860 & 73 \\
Central Area Council & Baare & 446 & 37 \\
& Tongo & 802 & 68 \\
East Area Council & Wakii & 246 & 21 \\
& Shega & 484 & 41 \\
& Tindongo & 317 & 27 \\
Total household sample & Gbanda-Yale & 216 & 426 \\
\hline
\end{tabular}

Information is based on the 2010 population and housing census for Talensi District. 
and Communication Technology (ICT) knowledge and use, farmer group membership, and length of stay in the community. These were all as categorical variables.

A pre-testing of the questionnaire was carried out among 30 participants in Gbeogo. This was a randomly selected community located within the Central Area Council and was not one of the nine sampled communities in the actual field survey. This process was useful for clarifying the ambiguous wording of some of the questions, and for guaranteeing the reliability of the data collection instrument, which was validated based on Cronbach's Alpha model. This model is generically known to measure internal consistency, based on the average inter-item correlation (Bryman 2008; Drost 2011). Bryman (2008) argued that a value of 0.80 is an acceptable level of internal reliability. From the pre-test of the instrument a Cronbach's Alpha of 0.906 was achieved. This value showed a $91 \%$ internal consistency in the items of the questionnaire. This means that the data collection instrument had excellent reliability.

The face-to-face interview technique was used to administer the questionnaire due to the high level of illiteracy among the crop farmers in the sample and the study area in general. The questionnaire was designed in English but translated into Talen, the primary dialect of Talensi District and then back into English. The content of the questionnaire captured issues on the sociodemographic characteristics of the households, the sources of early warning drought information, and the level of attentiveness to early warning drought information. The time spent on administering the questionnaire ranged between 30 minutes and one hour.

To guarantee compliance with ethical concerns of voluntarism, the researchers first explained the aims, research procedures, and voluntary nature of participation to the study participants and sought their consent before the questionnaire was administered. An informed consent form was prepared and issued to all participants to either thumbprint or sign. But the majority of the participants rather gave their verbal consent.

\subsection{Data Analysis}

The data analysis was carried out with the Statistical Package for Social Sciences (SPSS) version 20 and Excel Version 16. The demographic and socioeconomic characteristics and the level of attentiveness to early warning drought information of crop farmers were analyzed by descriptive technique of frequency table. The relative importance index (RII) was used to analyze and rank the sources of early warning drought information in Talensi District. To determine the predictive role of the demographic and socioeconomic characteristics on the level of attentiveness to early warning drought information among crop farmers, a multinomial logistic regression analysis was performed. The level of attentiveness was the dependent variable while the demographic and socioeconomic characteristics of the crop farmers served as the predictor variables of the model (Table 2). The test of statistical significance was measured at $\alpha=0.05$.

\section{Results}

This section presents the findings from the field survey in three categories: demographic and socioeconomic characteristics; sources of early warning drought information among crop farmers; and level and predictors of attentiveness to early warning drought information.

\subsection{Demographic and Socioeconomic Characteristics}

The findings in Table 3 show that more males (76.8\%) were involved in the survey than females. On average monthly income, $70.9 \%$ earned less than or equal to $\mathrm{GHC}$ 500. The finding on the level of formal education showed that 218 crop farmers $(51.2 \%)$ had never had any form of formal education. Of the surveyed crop farmers $93.7 \%$ acknowledged some form of religious affiliation. The majority of the crop farmers $(76.5 \%)$ were currently married. The overall participation of non-household heads was higher $(59.2 \%)$ than that of household heads, and $86.2 \%$ reported no ICT knowledge and use. A total of $58.2 \%$ affirmed farmer group membership.

The mean age was 49.8 years. The mean length of stay in the community of the crop farmers surveyed in the district was 36.61 years (standard deviation $=16.528$ years).

\subsection{Sources of Early Warning Drought Information among Crop Farmers in Talensi District}

The farmers ranked receiving information from agricultural extension officers as the first source of accessing early warning drought information (mean $=2.528, \mathrm{RII}=0.506$ or $50.6 \%$ ) (Table 4). This was followed by listening to radio and/or television broadcasts during weather report segments $($ mean $=1.723$, RII $=0.345$ or $34.5 \%$ ), followed by farmer group meetings $($ mean $=1.333$, RII $=0.267$ or $26.7 \%$ ), and community durbars held during festivals $($ mean $=1.230$, RII $=0.246$ or $24.6 \%)$. 
Table 2 Dependent and independent variables of the multinomial logistic model for the attentiveness to early warning drought information study in Talensi District, Ghana

\begin{tabular}{lll}
\hline Variable name & $\begin{array}{l}\text { Variable } \\
\text { Type }\end{array}$ & Coding \\
\hline $\begin{array}{l}\text { Dependent } \\
\text { Attentiveness }\end{array}$ & Categorical & $1=$ not at all, $2=$ a little, $3=$ very much \\
Predictors & Dichotomous & $0=$ female, $1=$ male \\
Gender & Dichotomous & $0=$ less than or equal to GHC 500, ${ }^{\text {a }} 1$ = more than GHC 500 \\
Average monthly income & Categorical & $0=$ no formal education, $1=$ basic education, $2=$ secondary education, $3=$ tertiary education \\
Level of formal education & Categorical & $0=$ Christianity, $1=$ Islam, $2=$ African Traditional, $3=$ no religion \\
Religion & Dichotomous & $0=$ not currently married, $1=$ currently married \\
Marital status & Dichotomous & $0=$ non-household heads, $1=$ household heads \\
Household status & Dichotomous & $0=$ no, $1=$ yes \\
ICT knowledge and use & Dichotomous & $0=$ no, $1=$ yes \\
Farmer group membership & Continuous & \\
Age & Continuous & \\
Length of stay in the community & \\
\hline
\end{tabular}

ICT, Information and Communication Technology.

${ }^{\mathrm{a}}$ As of March 2019, USD 1 = GHC 5.45 (Ghanaian Cedi).

\subsection{Level and Predictors of Attentiveness to Early Warning Drought Information}

Of the crop farmers surveyed in Talensi District 334 (78.4 $\%$ ) indicated that they pay a little to very much attention to early warning drought information, but a significant $21.6 \%$ (92 crop farmers) indicated that they do not pay any attention at all to early warning drought information (Fig. 2).

The dependent variable, attentiveness, was measured as a nominal variable. To model the relationship between the demographic and socioeconomic characteristics and attentiveness to early warning drought information, we employed a multinomial logistic regression. This provided us with the opportunity to explain the different levels of attentiveness to early warning drought information and to identify the significant demographic and socioeconomic characteristics that predict varied levels of attentiveness. Based on the analysis, the likelihood ratio chi-square test showed that the final model is a significant improvement in fit as $X^{2}(20)=96.792, p<0.000$ (Table 5). On the goodness-of-fit, the Pearson's chi-square test indicates that the model fits the data well $\left(X^{2}(804)=846.003, p=0.148\right)$. This was further authenticated by the deviance chi-square, which also indicated good fit $\left(X^{2}(804)=790.199, p=\right.$ 0.629 ).

The first part of Table 6 shows the relationship between the predictors and not paying attention at all to early warning drought information. Household status, average monthly income, and ICT knowledge and use were significant with positive coefficients $(\beta)$. The positive $\beta$ value for household status indicate that crop farmers who were non-household heads were 0.12 times or $12 \%$ less likely to pay no attention at all to early warning drought information $(\beta=0.880)$ compared with those paying very much attention. Crop farmers who earned $\leq$ GHC 500 had higher odds of not paying attention to early warning information and the odds increased by a factor of 0.540 times or $54 \%$ ( $\beta=1.540)$ compared with those paying very much pay attention to early warning drought information. Those with no ICT knowledge and use were 0.023 times or $2.3 \%$ less likely to pay no attention to early warning drought information $(\beta=0.977)$ compared with those paying very much attention to early warning drought information. Age, although a significant predictor, had a negative coefficient $(\beta=-0.035)$. This means that, a unit increase in the age of a crop farmer accounts for $95.6 \%$ likelihood of such a farmer paying no attention to early warning drought information. In other words, older crop farmers are more likely to pay no attention to early warning drought information.

In relation to the category of pay a little attention to early warning drought information, household status was the only predictor found to be significant. The positive coefficient $(\beta=0.784)$ revealed that compared with those paying very much attention, crop farmers who were nonhousehold heads were 0.216 times or $21.6 \%$ less likely to pay a little attention to early warning drought information.

The classification of the results (Table 7) shows that crop farmers who pay no attention at all to early warning 
Table 3 Demographic and socioeconomic characteristics of the surveyed crop farming households in Talensi District, Ghana

\begin{tabular}{|c|c|c|}
\hline Variables & Frequency & Percent $(\%)$ \\
\hline \multicolumn{3}{|l|}{ Gender } \\
\hline Male & 327 & 76.8 \\
\hline Female & 99 & 23.2 \\
\hline \multicolumn{3}{|l|}{ Average monthly income } \\
\hline$\leq \mathrm{GHC} 500$ & 302 & 70.9 \\
\hline$>$ GHC 500 & 124 & 29.1 \\
\hline \multicolumn{3}{|l|}{ Level of formal education } \\
\hline No formal education & 218 & 51.2 \\
\hline Basic education & 140 & 32.9 \\
\hline Secondary/technical/vocational school & 32 & 7.5 \\
\hline Tertiary & 36 & 8.5 \\
\hline \multicolumn{3}{|l|}{ Religious affiliation } \\
\hline Christianity & 175 & 41.1 \\
\hline Islam & 35 & 8.2 \\
\hline African traditional religion & 189 & 44.4 \\
\hline No religion & 27 & 6.3 \\
\hline \multicolumn{3}{|l|}{ Marital status } \\
\hline Currently not married & 100 & 23.5 \\
\hline Currently married & 326 & 76.5 \\
\hline \multicolumn{3}{|l|}{ Household Status } \\
\hline Household heads & 174 & 40.8 \\
\hline Non-household heads & 252 & 59.2 \\
\hline \multicolumn{3}{|l|}{ ICT knowledge and use } \\
\hline No & 367 & 86.2 \\
\hline Yes & 59 & 13.8 \\
\hline \multicolumn{3}{|l|}{ Farmer group membership } \\
\hline No & 178 & 41.8 \\
\hline Yes & 248 & 58.2 \\
\hline Total & 426 & 100 \\
\hline Descriptive statistics for continuous variables & Age (years) & Length of stay (years) \\
\hline Mean & 49.8 & 36.6 \\
\hline Standard deviation & 14.565 & 16.528 \\
\hline Variance & 212.134 & 273.161 \\
\hline
\end{tabular}

ICT, Information and Communication Technology.

Table 4 Ranking information sources for the surveyed crop farming households in Talensi District, Ghana

\begin{tabular}{|c|c|c|c|c|c|c|c|c|c|c|c|}
\hline Sources & 1 & 2 & 3 & 4 & 5 & $\mathrm{~N}$ & NA & $\sum \mathrm{W}$ & $\overline{\mathrm{x}}$ & RII & Rank \\
\hline Receiving information from agricultural extension officers & 167 & 30 & 92 & 111 & 26 & 426 & 2130 & 1077 & 2.528 & 0.506 & 1 \\
\hline $\begin{array}{l}\text { Listening to radio and television broadcasts (during weather report } \\
\text { segments) }\end{array}$ & 232 & 126 & 33 & 24 & 11 & 426 & 2130 & 734 & 1.723 & 0.345 & 2 \\
\hline Farmer group meetings & 354 & 35 & 13 & 15 & 9 & 426 & 2130 & 568 & 1.333 & 0.267 & 3 \\
\hline Community durbars & 388 & 12 & 2 & 14 & 10 & 426 & 2130 & 524 & 1.230 & 0.246 & 4 \\
\hline
\end{tabular}

1 = not reliable, 2 = less reliable, $3=$ uncertain, 4 = reliable, $5=$ very reliable, $\mathrm{N}=$ sample (426), $\mathrm{A}=$ highest ranking of Likert scale $(5), \sum \mathrm{W}=$ Sum of weights, $\bar{x}=$ Mean, $\mathrm{RII}=$ relative impact index. 
Fig. 2 Level of attentiveness to early warning drought information of the surveyed crop farming households in Talensi District, Ghana

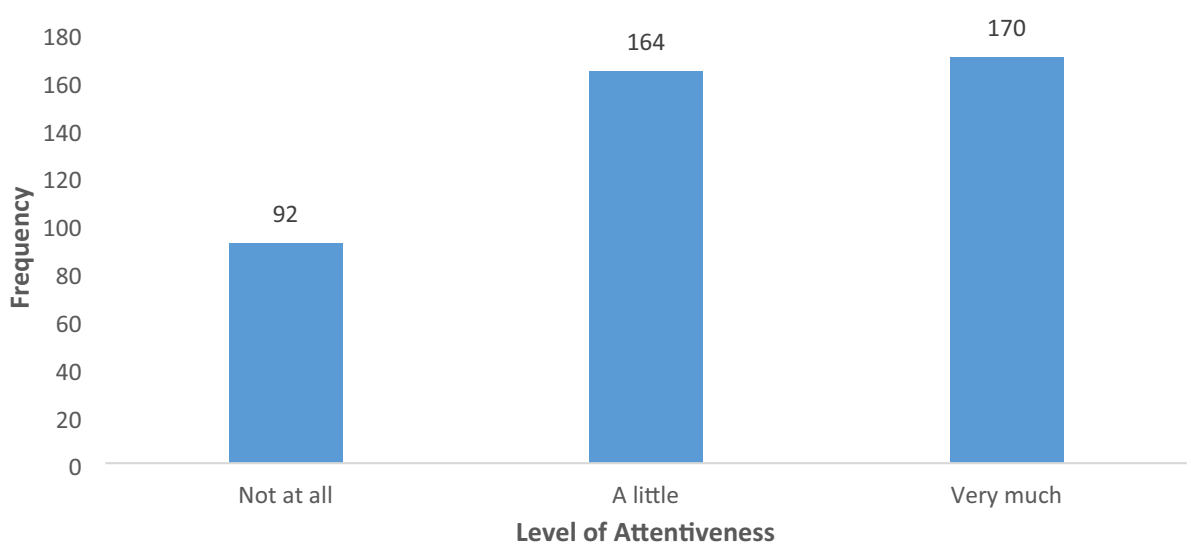

Table 5 Model fitting information, goodness-of-fit, and pseudo r-square in the attentiveness to early warning drought information study in Talensi District, Ghana

\begin{tabular}{|c|c|c|c|c|}
\hline \multicolumn{5}{|c|}{ Model fitting information } \\
\hline \multirow[t]{2}{*}{ Model } & \multirow{2}{*}{$\begin{array}{l}\text { Model fitting criteria } \\
-2 \text { Log likelihood }\end{array}$} & \multicolumn{3}{|c|}{ Likelihood ratio tests } \\
\hline & & Chi-square & Df & Significance \\
\hline Intercept only & 896.931 & & & \\
\hline Final & 800.139 & 96.792 & 20 & 0.000 \\
\hline \multicolumn{5}{|l|}{ Goodness-of-fit } \\
\hline Pearson & & 846.003 & 804 & 0.148 \\
\hline Deviance & & 790.199 & 804 & 0.629 \\
\hline \multicolumn{5}{|l|}{ Pseudo R-square } \\
\hline Cox and Snell & 0.203 & & & \\
\hline Nagelkerke & 0.231 & & & \\
\hline McFadden & 0.107 & & & \\
\hline
\end{tabular}

drought information were predicted best by the model. "Not at all" was correctly predicted by the model by $58.7 \%$. Overall, the model predicted slightly above average the job of prediction (52\%).

\section{Discussion}

The findings show that the study participants had an average length of stay in their communities of 37 years. This means that they have sufficient experience with the microclimate of the district. The mean age of 36 years indicates that the district has a youthful agricultural labor force. This can be an incentive to promoting sustainable development of the local economy if the right policies are fashioned for productive crop farming. More than half of the sampled participants did not have any formal education. This means there is a high level of illiteracy among crop farmers. The implication is that the understanding of the technical information necessary to promote actions to sustainably manage the farmers' livelihoods tends to be lacking. In particular, it may be difficult for crop farmers in the district to understand the technical assessments of climate change effects and early warning information. This finding ties in with Salite (2019) who stated that crop farmers in the global south lack understanding of the technical assessment of climate risk. The crop farmers in Talensi District may need assistance with interpreting the technical information that is communicated about drought risk in particular, and climate change in general. This would help them prepare and take appropriate actions for drought mitigation and adaptation. This brings to bear the critical role of agricultural extension officers whom the surveyed farmers in Talensi District ranked as being the first point of call, when they want to assess drought risk information (see Table 4). However, the current low ratio of extension officers to crop farmers in the district, and across Ghana in general, implies that the significant role of extension officers as brokers of information to help rural 
Table 6 Parameter estimates in the attentiveness to early warning drought information study in Talensi District, Ghana

\begin{tabular}{|c|c|c|c|c|c|c|c|c|}
\hline Level of attentiveness ${ }^{a}$ & $\beta$ & SE & Wald & Significance & $\operatorname{Exp}(\beta)$ & \multicolumn{2}{|c|}{$95 \% \mathrm{CI}$} & Reference category \\
\hline Not at all & & & & & & & & Very much \\
\hline Intercept & -2.677 & 1.249 & 4.594 & 0.032 & & & & \\
\hline Gender & -0.742 & 0.488 & 2.313 & 0.128 & 0.476 & 0.183 & 1.239 & Female \\
\hline Average monthly income & 1.540 & 0.346 & 19.874 & $0.000 * *$ & 4.667 & 2.371 & 9.186 & $>$ GHC 500 \\
\hline Formal education & -0.088 & 0.168 & 0.273 & 0.602 & 0.916 & 0.659 & 1.273 & Tertiary \\
\hline Religious affiliation & 0.262 & 0.168 & 2.414 & 0.120 & 1.299 & 0.934 & 1.808 & No religion \\
\hline Marital status & 0.776 & 0.419 & 3.433 & 0.064 & 2.173 & 0.956 & 4.940 & Currently married \\
\hline Household status & 0.880 & 0.338 & 6.802 & $0.009^{*}$ & 2.412 & 1.245 & 4.674 & Non-household heads \\
\hline ICT knowledge and use & 0.977 & 0.429 & 5.181 & $0.023 *$ & 2.657 & 1.145 & 6.162 & Yes \\
\hline Farmer group membership & -0.194 & 0.319 & 0.368 & 0.544 & 0.824 & 0.440 & 1.541 & Yes \\
\hline Age & -0.035 & 0.014 & 5.708 & $0.017 *$ & 0.966 & 0.939 & 0.994 & \\
\hline Length of stay in community & 0.017 & 0.012 & 1.957 & 0.162 & 1.017 & 0.993 & 1.042 & \\
\hline A little & & & & & & & & Very much \\
\hline Intercept & 1.775 & 0.895 & 3.930 & 0.047 & & & & \\
\hline Gender & -0.323 & 0.331 & 0.948 & 0.330 & 0.724 & 0.378 & 1.386 & Female \\
\hline Average monthly income & -0.155 & 0.313 & 0.246 & 0.620 & 0.856 & 0.463 & 1.582 & $>$ GHC 500 \\
\hline Formal education & -0.061 & 0.131 & 0.217 & 0.641 & 0.941 & 0.727 & 1.217 & Tertiary \\
\hline Religious affiliation & -0.150 & 0.128 & 1.375 & 0.241 & 0.861 & 0.670 & 1.106 & No religion \\
\hline Marital status & -0.109 & 0.271 & 0.161 & 0.688 & 0.897 & 0.527 & 1.525 & Currently married \\
\hline Household status & 0.784 & 0.273 & 8.267 & $0.004 *$ & 2.190 & 1.283 & 3.736 & Non-household heads \\
\hline ICT knowledge and use & 0.113 & 0.391 & 0.084 & 0.772 & 1.120 & 0.520 & 2.411 & Yes \\
\hline Farmer group membership & -0.317 & 0.233 & 1.846 & 0.174 & 0.729 & 0.462 & 1.150 & Yes \\
\hline Age & -0.007 & 0.009 & 0.555 & 0.456 & 0.993 & 0.976 & 1.011 & \\
\hline Length of stay in community & -0.004 & 0.008 & 0.187 & 0.665 & 0.996 & 0.980 & 1.013 & \\
\hline
\end{tabular}

$\beta=$ beta; SE, standard error; $\operatorname{Exp}(\beta)$, exponentiated coefficient; CI, confidence interval

$* * p<0.001 ; * p<0.05$

farmers prepare and plan for climate risk is currently limited.

Given that $94 \%$ of the surveyed crop farmers are religiously affiliated, local leaders of religious shrines and worship centers are poised as actors to facilitate and further serve as brokers of information on drought risk and other climate risks. Chanza et al. (2020) called for the participation of local actors to utilize their local-based response systems to manage to fill in the voids that characterize disaster management practice. While ICT knowledge and use is useful to access information, $86 \%$ of the surveyed crop farmers do not have knowledge and usage of ICT to access the early warning drought information. This is partly explained by the high illiteracy level among crop farmers in the district. A significant $22 \%$ of the surveyed crop farmers living and working in the drought-prone areas of Talensi District are indifferent as to whether there is early information to warn them about drought or not. To promote sustainable drought management in the district, and Ghana as a whole, more attention needs to be paid to the kind of information that is generated as well as the risk communication strategies that are employed to disseminate drought risk information to crop farmers. If the early warning information generated is too technical crop farmers will not be able to understand it given that the majority of them do not have any formal education (see Table 3 ).

The drought risk communication needs to be considered. According to Marchezini (2020), risk communication is the process of sharing data, information, and knowledge about the risks (hazards and vulnerabilities), and warning situations. But it is not enough to only consider the risk communication but more importantly the attentiveness to the message is tied to the spatial psychological distance (Ejelöv et al. 2018). In particular, the spatial dimension of the psychological distance indicates that when an event is seen to take place far away geographically, it makes people perceive and process it to be typically farther away than it actually is (Ejelöv et al. 2018). The argument is that, for drought management at the local level to be sustainable, the early warning drought information should not be 
Table 7 Classification of the results from the attentiveness to early warning drought information study of crop farming households in Talensi District, Ghana

\begin{tabular}{lllll}
\hline Observed & Predicted & & & \\
\cline { 2 - 5 } & Not at all & A little & Very much & Percent correct $(\%)$ \\
\hline Not at all & 54 & 23 & 15 & 58.7 \\
A little & 21 & 80 & 63 & 48.8 \\
Very much & 22 & 62 & 86 & 50.6 \\
Overall percentage & $22.8 \%$ & $38.7 \%$ & $38.5 \%$ & 51.6 \\
\hline
\end{tabular}

communicated to be spatially distanced. This will foster a better drought perception and information processing to initiate strategies for drought planning and ultimately sustainable management of drought effects. Pragmatic efforts are required to reduce the level of abstractness in the communication of early warning drought information to crop farmers in order not to make them more susceptible. According to Ledgerwood et al. (2010), when people are subjected to abstract thinking it makes them susceptible to influences of other abstract, high-level information such as values and attitudes.

The need to understand the levels of attentiveness to early warning drought information and the factors predicting these among crop farmers cannot be overestimated. Talensi District is part of the estimated 35\% drought-prone area of Ghana (UNECA 2007). As a result of the high exposure to drought, it is reasonable to expect crop farmers whose livelihood is most sensitive to drought to pay very much attention to early warning drought information. Thus, using very much attention as the reference category, the study identified the factors that predict the likelihood of crop farmers choosing either to pay no attention at all or a little attention to early warning drought information. The significant demographic, social, and economic characteristics of the surveyed crop farmers that influence their odds of choosing to not pay attention to early warning drought information in the context of Talensi District are household status, average monthly income, ICT knowledge and use, and age. In relation to those who pay a little attention, household status was the only significant variable. These findings have significance for policy in a number of dimensions.

Ghana has adopted the National Climate Change Policy (NCCP) as its integrated response to climate change (Lawson 2016). The policy has the three specific objectives of effective adaptation, social development, and mitigation. The NCCP was developed from the National Climate Change Policy Framework (NCCPF) (MESTI 2013). The NCCPF was a discussion document with focus on the concept of "Ghana Goes for Green Growth, G4." Within this framework, the national goal is to build a climateresilient society that can rely on effective early warning and response systems, where everyone has a broad understanding of climate hazards. The extent to which this goal will receive support from local-level participants like crop farmers is contingent on their level of attentiveness (Switzer and Vedlitz 2017; Torres et al. 2020). Of the surveyed crop farmers in Talensi District 60\% were paying no attention to a little attention to early warning drought information (see Fig. 2). This means that the likelihood that they support the national goal to develop climate early warning centers for the effective understanding of climate risks like drought occurrence is lowered by up to $60 \%$. Based on the findings in Table 6, crop farmers who were non-household heads will likely exhibit $12 \%$ to $22 \%$ less support for any environmental policy on the development of effective early warning systems for drought monitoring. Likewise, crop farmers earning $\leq$ GHC 500 were $54 \%$ less likely to very much support drought risk reduction policies. Additionally, as crop farmers grow older, they were $97 \%$ less likely to very much support any policy on early warning systems in Talensi District in particular, and Ghana at large.

Weiss and Cropanzano (1996) stated that affect is a personality trait that generally predicts emotional tendencies or moods. Thus, attentiveness as a unit of affect provides insight into the personality traits of the surveyed crop farmers in Talensi District. Therefore, the level of attentiveness of crop farmers as found in this study provides a clue to the general emotions and moods. Moods in particular relate to cognitive competencies (Morris 2003). Sörqvist and Langeborg (2019) stated that environmentally harmful behavior and decision making often have their roots in cognitive biases and cognitive inabilities to properly understand climate change issues, to understand the effects of one's own behavior on the environment, and other means by which thinking and reasoning about climate change are biased. Xie et al. (2018) similarly argued that faulty mental models cause individuals to misunderstand carbon dioxide $\left(\mathrm{CO}_{2}\right)$ systems. They indicated that 
individuals underestimate the emission reduction required to stabilize atmospheric carbon dioxide levels and this often causes people to endorse ineffective "wait-and-see" climate policies. The classification of the results (see Table 7) indicates that the crop farmers who pay no attention at all to early warning drought information was the result best predicted (59\%) by the model. Based on the arguments of Xie et al. (2018) and Sörqvist and Langeborg (2019), the 59\% who pay no attention to early warning drought information in Talensi District have high probability of misunderstanding and/or underestimating how their own behaviors contribute to environmental damage. In addition, it means that these crop farmers are 59\% more likely to adopt a laissez-faire attitude towards actions required of them for climate risk reduction.

Luo and Zhao (2019) argued that attentional biases influence subsequent actions to mitigate climate change. This means that the actions taken by crop farmers differ in the different categories of attention in order to mitigate climate change in general and drought in particular in Talensi District. Based on the results in Fig. 2, the crop farmers who pay no to a little attention to early warning drought information are $60 \%$ more likely to adopt reactive strategies in responding to drought effects in the study area. It is conceivable that about $60 \%$ of crop farmers are not well poised to succeed in sustainable drought management in the Talensi District and drought-prone Ghana as a whole. Thus, attention as an emotional trait significantly predicts how people act with respect to climate risk reduction. This ties in with Ejelöv et al. (2018) who state that emotions mediate readiness to act against climate change threat and the level of success.

Crop farmers in the study area accessed drought risk information from agricultural extension officers. However, in the light of the limited number of extension officers to the crop farmer population in the district and across Ghana in general, researchers are increasingly calling for the need for crop farmers to begin to pay for timely early warning information from privately established weather platforms. Antwi-Agyei et al. (2020) found that farmers in the Upper East Region of Ghana are willing to pay to access climate information though this is significantly dependent on factors such as drought experience, food insecurity, farming experience, government subsidies, membership of a social group, and training. Our findings on the level of attentiveness are crucial in determining the success of crop farmers' willingness to pay to access climate information. In particular, the willingness to pay for climate information will be $60 \%$ lower among crop farmers who are nonhousehold heads, earn $\leq$ GHC 500, have no ICT knowledge and use, and are older in drought-prone Ghana. This is because these categories of crop farmers were $60 \%$ willing to pay no attention at all or a little attention to early warning drought information in the case of Talensi District. The implication is that, to promote a policy of crop farmers paying to access climate information, the moderating role of level of attentiveness to early warning information should be considered.

\section{Conclusion}

Based on the results and discussion of the survey in Talensi District, three key conclusions can be drawn. First, the useful role of agricultural extension officers as brokers of climate risk information to rural crop farmers in the district is minimal. This is due to the limited number of extension officers. Therefore, to overly rely on agricultural extension officers to facilitate effective drought risk communication among crop farmers is not the best policy option in Talensi District and other drought-prone areas in Ghana. To harness their useful role, a pragmatic policy that focuses on recruiting and training more agricultural extension officers, should be pursued. Second, the drive to build a climateresilient society with effective early warning centers across Ghana, and the Talensi District in particular, will receive 60\% lower support from crop farmers in Talensi District$60 \%$ stated they pay no to a little attention to early warning drought information compared with those paying very much attention. Third, little to no attentiveness to early warning drought information may result in less willingness on the part of crop farmers to pay for early warning information from privately established weather platforms. The Ghana Meteorological Agency (GMet) should collaborate with the District Directorate of Agriculture in order to strengthen the community information centers to serve as brokers of early warning information for climate risk reduction in drought-prone districts including Talensi. The design and pursuit of drought mitigation and adaptation strategies should be carried out along the three levels of crop farmers' attentiveness to early warning drought information. Finally, broader stakeholder engagements are required to harness inclusive support from crop farmers to build a climate-resilient society in Ghana. In such deliberations, it is very useful to consider the mediating role of demographic, social, and economic factors like household status, average monthly income, ICT knowledge and use, and age, since these significantly predict the level of attentiveness to early warning information.

Acknowledgments We gratefully acknowledge the support and cooperation received from the crop farmers in Talensi District during the field survey.

Open Access This article is licensed under a Creative Commons Attribution 4.0 International License, which permits use, sharing, adaptation, distribution and reproduction in any medium or format, as 
long as you give appropriate credit to the original author(s) and the source, provide a link to the Creative Commons licence, and indicate if changes were made. The images or other third party material in this article are included in the article's Creative Commons licence, unless indicated otherwise in a credit line to the material. If material is not included in the article's Creative Commons licence and your intended use is not permitted by statutory regulation or exceeds the permitted use, you will need to obtain permission directly from the copyright holder. To view a copy of this licence, visit http://creativecommons. org/licenses/by/4.0/.

\section{References}

Abdul-Razak, M., and S. Kruse. 2017. The adaptive capacity of smallholder farmers to climate change in the Northern Region of Ghana. Climate Risk Management 17: 104-122.

Alhakami, A.S., and P. Slovic. 1994. A psychological study of the inverse relationship between perceived risk and perceived benefit. Risk Analysis 14(6): 1085-1096.

Allen, K. 2003. Vulnerability reduction and the community-based approach. In Natural disasters and development in a globalizing world, ed. M. Pelling, 170-184. London: Routledge.

Aninagyei, I., and D.O. Appiah. 2014. Analysis of rainfall and temperature effects on maize and rice production in Akim Achiase, Ghana. Scholars Academic Journal of Biosciences (SAJB) 2(12B): 930-942.

Antwi-Agyei, P., K. Amanor, J.N. Hogarh, and A.J. Dougill. 2020. Predictors of access to and willingness to pay for climate information services in north-eastern Ghana: A gendered perspective. Environmental Development 37(12): Article 100580.

Antwi-Agyei, P., L.C. Stringer, and A.J. Dougill. 2014. Livelihood adaptations to climate variability: Insights from farming households in Ghana. Regional Environmental Change 14(4): 16151626.

Appiah, D.O., and J. Boafo. 2014. Analysis of temperature anomalies as proxy to climate variability and change in a peri-urban district, Ghana. Advanced Journal of Environmental Management 1(3): 20-33.

Ault, T.R., J.E. Cole, J.T. Overpeck, G.T. Pederson, and D.M. Meko. 2014. Assessing the risk of persistent drought using climate model simulations and paleoclimate data. Journal of Climate 27 (20): 7529-7549.

Bang, H.N. 2008. Social vulnerability and risk perception to natural hazards in Cameroon two decades after the Lake Nyos gas disaster: What future prospect for the displaced disaster victims? Paper presented at the 2008 Summer Academy for Social Vulnerability at the United Nations University - Institute for Environment and Human Security (UNU-EHS), Germany. http:// citeseerx.ist.psu.edu/viewdoc/summary?doi=10.1.1.471.6902. Accessed 10 Jan 2020.

Baudoin, M.A., S. Henly-Shepard, N. Fernando, A. Sitati, and Z. Zommers. 2014. Early warning systems and livelihood resilience: Exploring opportunities for community participation. UNU-EHS Working Paper Series No.11. Bonn: United Nations University - Institute for Environment and Human Security (UNU-EHS).

Binita, K.C., J.M. Shepherd, and C.J. Gaither. 2015. Climate change vulnerability assessment in Georgia. Applied Geography 62: 6274.

Boken, V.K. 2009. Improving a drought early warning model for an arid region using a soil-moisture index. Applied Geography 29 (3): 402-408.
Brooks, N. 2003. Vulnerability, risk and adaptation: A conceptual framework. Working Paper 38. Norwich, UK: Tyndall Centre for Climate Change Research, University of East Anglia.

Bryman, A. 2008. Social research methods, 3rd edn. New York: Oxford University Press.

Burchfield, E.K., and J. Gilligan. 2016. Agricultural adaptation to drought in the Sri Lankan dry zone. Applied Geography 77: 92100.

Chanza, N., P.Q. Siyongwana, L. Williams-Bruinders, V. GunduJakarasi, C. Mudavanhu, V.B. Sithole, and A. Manyani. 2020. Closing the gaps in disaster management and response: Drawing on local experiences with Cyclone Idai in Chimanimani, Zimbabwe. International Journal of Disaster Risk Science 11 (5): 655-666.

Cunha, A.P.M.A., V. Marchezini, D.P. Lindoso, S.M. Saito, and R.C. S. Alvalá. 2019. The challenges of consolidation of a droughtrelated disaster risk warning system to Brazil. Sustainability in Debate 10(1): Article 50.

Drost, E.A. 2011. Validity and reliability in social science research. Education Research and Perspectives 38(1): Article 105.

Ejelöv, E., A. Hansla, M. Bergquist, and A. Nilsson. 2018. Regulating emotional responses to climate change - A construal level perspective. Frontiers in Psychology 9: Article 629.

Ember, C.R., I. Skoggard, B. Felzer, E. Pitek, and M. Jiang. 2021. Climate variability, drought, and the belief that high gods are associated with weather in nonindustrial societies. Weather, Climate, and Society 13(2): 259-272.

GSS (Ghana Statistical Service). 2014. 2010 population and housing census analytical report, Talensi District. http://www2.stats ghana.gov.gh/docfiles/2010_District_Report/Upper\%20East/ TALENSI.pdf. Accessed 10 Jan 2019.

Lawson, E.T. 2016. Negotiating stakeholder participation in the Ghana national climate change policy. International Journal of Climate Change Strategies and Management 8(3): 399-417.

Ledgerwood, A., Y. Trope, and S. Chaiken. 2010. Flexibility now, consistency later: Psychological distance and construal shape evaluative responding. Journal of Personality and Social Psychology 99(1): 32-51.

Luo, Y., and J. Zhao. 2019. Motivated attention in climate change perception and action. Frontiers in Psychology 10: Article 1541.

Marchezini, V. 2020. "What is a sociologist doing here?" An unconventional people-centered approach to improve warning implementation in the Sendai Framework for Disaster Risk Reduction. International Journal of Disaster Risk Science 11(2): 218-229.

MESTI (Ministry of Environment, Science, Technology and Innovation, Republic of Ghana). 2013. Ghana national climate change policy. https://www.greengrowthknowledge.org/national-docu ments/ghana-national-climate-change-policy. Accessed 24 Nov 2020.

Mishra, K.A., and V.P. Singh. 2010. A review of drought concepts. Journal of Hydrology 391: 202-216.

Morris, W.N. 2003. The mood system. In Well-being: Foundations of hedonic psychology, ed. D. Kahneman, E. Diener, and N. Schwarz, 169-189. New York: Russell Sage Foundation.

Muguti, T., and R.S. Maposa. 2012. Indigenous weather forecasting: A phenomenological study engaging the Shona of Zimbabwe. The Journal of Pan African Studies 4(9): 102-111.

Owusu, M., M. Nursey-Bray, and D. Rudd. 2019. Gendered perception and vulnerability to climate change in urban slum communities in Accra, Ghana. Regional Environmental Change 19(1): 13-25.

Radeva, K., N. Nikolova, and M. Gera. 2018. Assessment of hydrometeorological drought in the Danube Plain, Bulgaria. Hrvatski Geografski Glasnik 80(1): 7-25. 
Ramkar, P., and S.M. Yadav. 2018. Spatiotemporal drought assessment of a semi-arid part of middle Tapi River Basin, India. International Journal of Disaster Risk Reduction 28: 414-426.

Salite, D. 2019. Explaining the uncertainty: Understanding smallscale farmers' cultural beliefs and reasoning of drought causes in Gaza Province, Southern Mozambique. Agriculture and Human Values 36(3): 427-441.

Saunders, M., P. Lewis, and A. Thornhill. 2007. Research methods for business students, 4th edn. Harlow, UK: Pearson Education.

Sörqvist, P., and L. Langeborg. 2019. Why people harm the environment although they try to treat it well: An evolutionary-cognitive perspective on climate compensation. Frontiers in Psychology 10: 348.

Sundblad, E.L., A. Biel, and T. Gärling. 2007. Cognitive and affective risk judgements related to climate change. Journal of Environmental Psychology 27(2): 97-106.

Switzer, D., and A. Vedlitz. 2017. Investigating the determinants and effects of local drought awareness. Weather, Climate, and Society 9(4): 641-657.

Tadesse, G., and M. Dejere. 2018. Impact of climate change on smallholder dairy production and coping mechanism in SubSaharan Africa - Review. Agricultural Resource Technology 16 (4): Article 43.

Tadesse, T., M. Haile, G. Senay, B.D. Wardlow, and C.L. Knutson. 2008. The need for integration of drought monitoring tools for proactive food security management in sub-Saharan Africa. Natural Resources Forum 32(4): 265-279.

Taylor, S.E. 1991. Asymmetrical effects of positive and negative events: The mobilization-minimization hypothesis. Psychological Bulletin 110(1): Article 67.

Torres, A.B., P.L. Vargas, and J. Paavola. 2020. The systemic and governmental agendas in presidential attention to climate change in Mexico 1994-2018. Nature Communications 11(1): 1-11.

UNECA (United Nations Economic Commission for Africa). 2007. Africa review report on drought and desertification.
In Proceedings of the Fifth Meeting of the Africa Committee on Sustainable Development (ACSD-5) Regional Implementation Meeting (RIM) for CSD-16, 22-25 October 2007, Addis Ababa, Ethiopia: 1-65. https://hdl.handle.net/10855/14921. Accessed 20 Aug 2019.

UNISDR (United Nations International Strategy for Disaster Reduction). 2009. Drought risk reduction framework and practices: Contributing to the implementation of the Hyogo Framework for Action. Geneva, Switzerland: UNISDR. https://www.unisdr.org/ files/3608_droughtriskreduction.pdf. Accessed 20 Aug 2019.

Watson, D., L.A. Clark, and A. Tellegen. 1988. Development and validation of brief measures of positive and negative affect: The PANAS scales. Journal of Personality and Social Psychology 54 (6): Article 1063.

Weiss, H.M., and R. Cropanzano. 1996. Affective events theory: A theoretical discussion of the structure, causes and consequences of affective experiences at work. https://www.researchgate.net/ profile/Russell-Cropanzano/publication/228079335_Affective_ Events_Theory_A_Theoretical_Discussion_of_The_Structure_ Cause_and_Consequences_of_Affective_Experiences_at_Work/ links/59e13575458515393d534b8e/Affective-Events-Theory-ATheoretical-Discussion-of-The-Structure-Cause-and-Conse quences-of-Affective-Experiences-at-Work.pdf. Accessed 20 Dec 2021.

Wilhite, D.A. 2006. Drought monitoring and early warning: Concepts, progress and future challenges. Washington, DC: World Meteorological Organization.

Wrigley-Asante, C., K. Owusu, I.S. Egyir, and T.M. Owiyo. 2019. Gender dimensions of climate change adaptation practices: The experiences of smallholder crop farmers in the transition zone of Ghana. African Geographical Review 38(2): 126-139.

Xie, B., M.J. Hurlstone, and I. Walker. 2018. Correct me if I'm wrong: Groups outperform individuals in the climate stabilization task. Frontiers in Psychology 9: Article 2274. 